\title{
Radiative Flow Past an Accelerated Vertical Plate with Variable Temperature and Uniform Mass Diffusion
}

\author{
Muralidharan M. and Muthucumaraswamy R.
}

\begin{abstract}
An exact solution of unsteady flow past a uniformly accelerated infinite vertical plate with variable temperature and mass diffusion, in the presence of thermal radiation is presented here. The dimensionless governing equations are solved using Laplace-transform technique. The velocity profiles, temperature and concentration are studied for different physical parameters like thermal Grashof number, mass Grashof number, Schmidt number, Prandtl number and time. It is observed that the velocity increases with increasing values of thermal Grashof number or mass Grashof number. But the trend is just reversed with respect to the thermal radiation parameter. It is also observed that there is a fall in plate temperature due to high thermal radiation.
\end{abstract}

Index Terms-Accelerated, vertical plate, heat and mass transfer, variable temperature, radiation.

\section{INTRODUCTION}

Heat and mass transfer in the presence of thermal radiation play an important role in manufacturing industries for the design of fins, steel rolling, nuclear power plants, gas turbines and various propulsion device for aircraft, combustion and furnace design, materials processing, energy utilization, temperature measurements, food processing and cryogenic engineering, as well as numerous agricultural, health and military applications. If the temperature of the surrounding fluid is rather high, radiation effects play an important role and this situation does exist in space technology.

England and Emery [1] have studied the thermal radiation effects of a optically thin gray gas bounded by a stationary vertical plate. Radiation effect on mixed convection along a isothermal vertical plate were studied by Hossain and Takhar [2]. Raptis and Perdikis [3] studied the effects of thermal radiation and free convection flow past a moving vertical plate. The governing equations were solved analytically. Das et al. [4] have analyzed radiation effects on flow past an impulsively started infinite isothermal vertical plate. The dimensionless governing equations were solved by the usual Laplace-transform technique.

Gupta et al. [5] studied free convection on flow past a linearly accelerated vertical plate in the presence of viscous dissipative heat using perturbation method. Kafousias and Raptis [6] extended the above problem to include mass

Manuscript received March 20, 2013; revised May 30, 2013.

Muralidharan M. is with the Department of Mathematics, Mohamed Sathak A. J. College of Engineering, Siruseri, IT Park, Chennai 603 103, India (e-mail: mu_anish@yahoo.co.in)

Muthucumaraswamy R. is with the Department of Applied Mathematics, Sri Venkateswara College of Engineering, Sriperumbudur 602 105, India (e-mail: msamy@svce.ac.in) transfer effects subjected to variable suction or injection. Mass transfer effects on flow past a uniformly accelerated vertical plate was studied by Soundalgekar [7]. Again, mass transfer effects on flow past an accelerated vertical plate with uniform heat flux was analyzed by Singh and Singh [8]. Basant Kumar Jha and Ravindra Prasad [9] analyzed mass transfer effects on the flow past an accelerated infinite vertical plate with heat sources. Recently, Muthucumaraswamy et al. [10] studied heat and mass transfer effects on flow past an accelerated vertical plate with variable mass diffusion with in absence of thermal radiation.

Hence, it is now proposed to study heat and mass transfer effects on unsteady flow past a uniformly accelerated infinite vertical plate with variable temperature in the presence of thermal radiation. The dimensionless governing equations are solved using the Laplace-transform technique. The solutions are in terms of exponential and complementary error function. Such a study found useful process industries such as wire drawing, fibre drawing, food processing and polymer production.

\section{Mathematical Formulation}

The unsteady flow of a viscous incompressible fluid past a uniformly accelerated vertical infinite plate with variable temperature and uniform mass diffusion has been considered. The $\mathrm{x}$-axis is taken along the plate in the vertically upward direction and the y-axis is taken normal to the plate. At time $t^{\prime} \leq 0$, the plate and fluid are at the same temperature $T_{\infty}$ and concentration $C_{\infty}^{\prime}$. At time $t^{\prime}>0$, the plate is accelerated with a velocity $u=\frac{u_{0}^{3}}{v} t^{\prime}$ in its own plane and the temperature from the plate is raised to $T_{w}$ and the mass is diffused from the plate to the fluid linearly with time. Then under usual Boussinesq's approximation the unsteady flow is governed by the following dimensionless equations as discussed in Muralidharan and Muthucumaraswamy [11].

$$
\begin{gathered}
\frac{\partial U}{\partial t}=G r \theta+G c C+\frac{\partial^{2} U}{\partial Y^{2}} \\
\frac{\partial \theta}{\partial t}=\frac{1}{P r} \frac{\partial^{2} \theta}{\partial Y^{2}}-\frac{R}{P r} \theta \\
\frac{\partial C}{\partial t}=\frac{1}{S c} \frac{\partial^{2} C}{\partial Y^{2}}
\end{gathered}
$$

The initial and boundary conditions in nondimensional quantities are 


$$
\begin{gathered}
U=0, \quad \theta=0, \quad C=0 \text { for all } Y, t \leq 0 \\
t>0: U=t, \quad \theta=\mathrm{t}, \quad C=1 \text { at } Y=0 \\
U \rightarrow 0, \quad \theta \rightarrow 0, \quad C \rightarrow 0 \text { as } Y \rightarrow \infty
\end{gathered}
$$

The dimensionless governing equations (1) to (3), subject to the initial and boundary conditions (4) are solved by the usual Laplace-transform technique and the solutions are derived as follows:

$$
C=\operatorname{erfc}(\eta \sqrt{S c})
$$

$$
\begin{aligned}
\theta=\frac{t}{2} & {\left[e^{2 \eta \sqrt{R t}} \operatorname{erfc}(\eta \sqrt{\operatorname{Pr}}+\sqrt{b t})+e^{-2 \eta \sqrt{R t}} \operatorname{erfc}(\eta \sqrt{\operatorname{Pr}}-\sqrt{b t})\right] } \\
& -\frac{\eta \sqrt{\operatorname{Pr} t}}{2 \sqrt{b}}\left[e^{-2 \eta \sqrt{R t}} \operatorname{erfc}(\eta \sqrt{\operatorname{Pr}}-\sqrt{b t})-e^{2 \eta \sqrt{R t}} \operatorname{erfc}(\eta \sqrt{\operatorname{Pr}}+\sqrt{b t})\right]
\end{aligned}
$$$$
U=t(1+2 a c-d)\left[\left(1+2 \eta^{2}\right) \operatorname{erfc}(\eta)-\frac{2 \eta}{\sqrt{\pi}} e^{-\eta^{2}}\right]
$$

$$
+2 a \operatorname{erfc}(\eta)
$$

$$
\begin{aligned}
& -a e^{c t}\left[e^{2 \eta \sqrt{c t}} \operatorname{erfc}(\eta+\sqrt{c t})+e^{-2 \eta \sqrt{c t}} \operatorname{erfc}(\eta-\sqrt{c t})\right] \\
& -a\left[e^{2 \eta \sqrt{R t}} \operatorname{erfc}(\eta \sqrt{\operatorname{Pr}}+\sqrt{b t})+e^{-2 \eta \sqrt{R t}} \operatorname{erfc}(\eta \sqrt{\operatorname{Pr}}-\sqrt{b t})\right] \\
& -a c t .\left[e^{2 \eta \sqrt{R t}} \operatorname{erfc}(\eta \sqrt{\operatorname{Pr}}+\sqrt{b t})+e^{-2 \eta \sqrt{R t}} \operatorname{erfc}(\eta \sqrt{\operatorname{Pr}}-\sqrt{b t})\right] \\
& +\frac{a c \eta \sqrt{\operatorname{Pr} t}}{\sqrt{b}}\left[e^{-2 \eta \sqrt{R t}} \operatorname{erfc}(\eta \sqrt{\operatorname{Pr}}-\sqrt{b t})-e^{2 \eta \sqrt{R t}} \operatorname{erfc}(\eta \sqrt{\operatorname{Pr}}+\sqrt{b t})\right] \\
& +a e^{c t}\left[e^{-2 \eta \sqrt{\operatorname{Pr}(b+c) t}} \operatorname{erfc}(\eta \sqrt{\operatorname{Pr}}-\sqrt{(b+c) t})+\right. \\
& +t d\left[\left(1+2 \eta^{2} S c\right) \operatorname{erfc}(\eta \sqrt{S c})-\frac{2 \eta \sqrt{S c}}{\sqrt{\pi}} e^{-\eta^{2} S c}\right]
\end{aligned}
$$

where

$\mathrm{b}=\frac{R}{P r}, \mathrm{a}=\frac{G r}{2 \mathrm{c}^{2}(1-P r)}, d=\frac{G c}{1-S c}$ and $c=\frac{R}{1-P r}$ and $\eta=Y / 2 \sqrt{t}$

\section{RESUlTS AND DisCUSSION}

For physical understanding of the problem, numerical computations are carried out for different physical parameters $G r, G c, S c, P r$ and $t$ upon the nature of the flow and transport. The value of the Schmidt number Sc is taken to be 0.6 which corresponds to water-vapour. Also, the value of Prandtl number $P r$ is chosen such that they represent air $(P r=0.71)$. The numerical values of the velocity, temperature and concentration are computed for different physical parameters like thermal radiation, Prandtl number, thermal Grashof number, mass Grashof number, Schmidt number and time.

The effect of velocity for different values of the radiation parameter $(R=0.2,5,20)$ are shown in Fig. 1 . The trend shows that the velocity increases with decreasing radiation parameter. It is observed that the velocity decreases in the presence of high thermal radiation. Fig. 2, demonstrates the effects of different thermal Grashof number $(G r=2,10)$, mass Grashof number $(G c=2,5)$ on the velocity at time $\mathrm{t}=$ 0.3 . It is observed that the velocity increases with increasing values of the thermal Grashof number or mass Grashof number. The velocity profiles for different $(t=0.2,0.3,0.4)$ are studied and presented in Fig. 3. It is observed that the velocity increases with increasing values of $t$.

The temperature profiles are calculated for different values of thermal radiation parameter $(R=0.2,2,5,10)$ are shown in Fig. 4 , in the presence of air $(P r=0.71)$. The effect of thermal radiation parameter is important in temperature profiles. The trend shows that the temperature increases with decreasing radiation parameter. Fig. 5 is a graphical representation which depicts the temperature profiles for different values of the time $(t=0.2,0.4,0.6,1)$ in the presence of thermal radiation. It is clear that the temperature increases with increasing values of the time $t$.

Fig. 6 represents the effect of concentration profiles at time $t=0.2$ for different Schmidt number $(S c=0.16,0.3$, $0.6,2.01)$. The effect of Schmidt number plays an important role in concentration field. The profiles have the common feature that the concentration decreases in a monotone fashion from the surface to a zero value far away in the free stream. It is observed that the wall concentration increases with decreasing values of the Schmidt number.

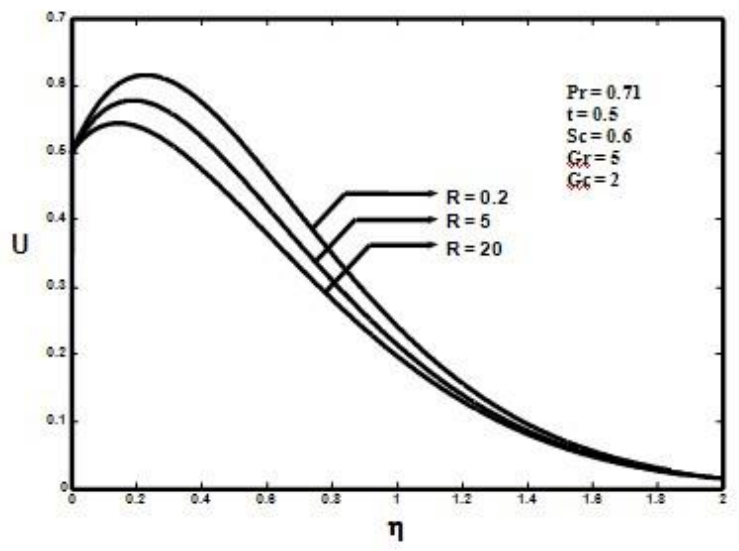

Fig. 1. Velocity profiles for different values of $R$

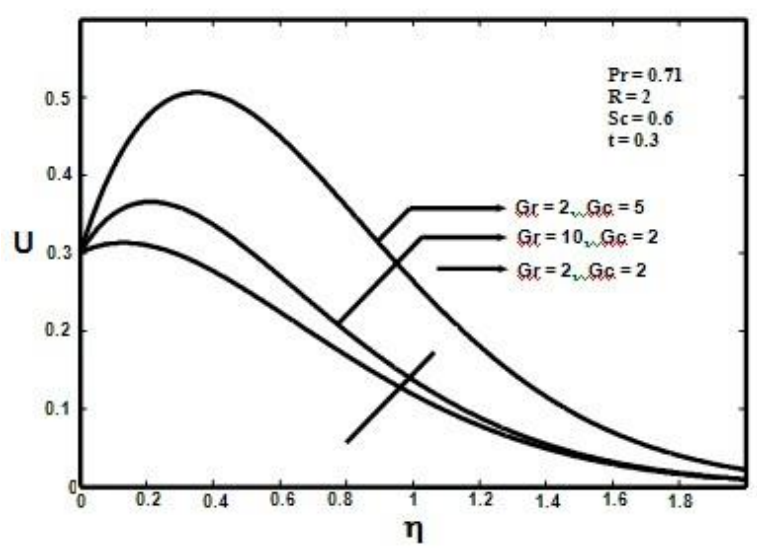

Fig. 2. Velocity profiles for different values of Gr, Gc 


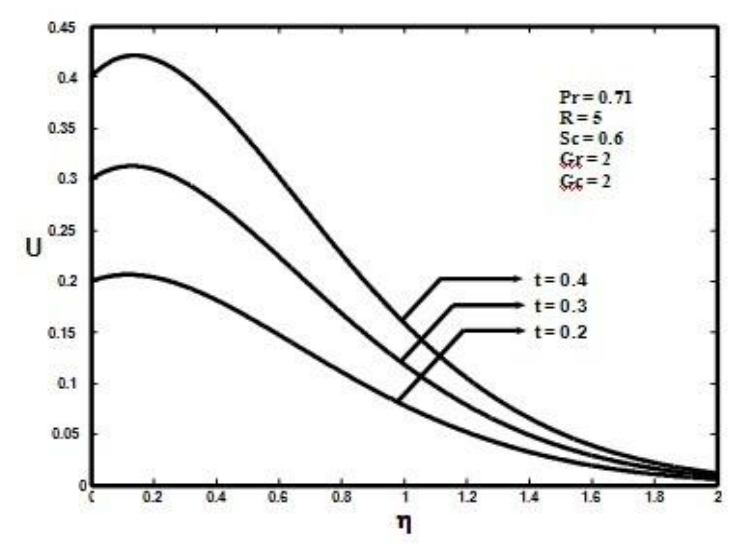

Fig. 3. Velocity profiles for different values of $t$



Fig. 4. Temperature profiles for different values of $R$

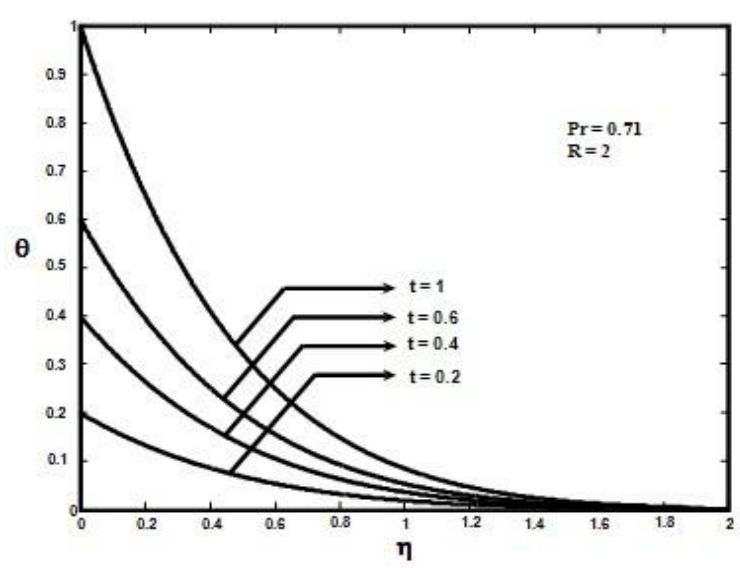

Fig. 5. Temperature profiles for different values of $t$

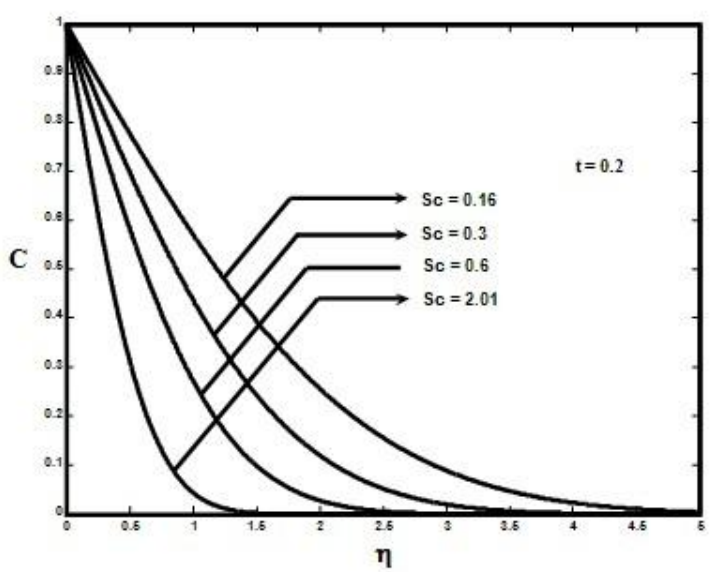

Fig. 6. Concentration profiles for different values of Sc

\section{CONCLUSION}

The theoretical solution of flow past a uniformly accelerated infinite vertical plate in the presence of variable temperature and uniform mass diffusion has been studied. The dimensionless governing equations are solved by the usual Laplace-transform technique. The effect of different parameters like thermal Grashof number, mass Grashof number, Schmidt number and time t are studied graphically. It is observed that the velocity increases with increasing values of $G r, G c$ and $t$. But the trend is just reversed with respect to the thermal radiation parameter. The plate temperature decreases due to high thermal radiation.

\section{NOMENClATURE, GREEK SyMBOLS}

$a^{*} \quad$ absorption coefficient

$C^{\prime} \quad$ species concentration in the fluid

C dimensionless concentration

$C_{w} \quad$ wall concentration

$C_{\infty} \quad$ concentration in the fluid far away from the plate

$C_{p} \quad$ specific heat at constant pressure

D mass diffusion coefficient

Gc mass Grashof number

Gr thermal Grashof number

$g \quad$ acceleration due to gravity

$k \quad$ thermal conductivity of the fluid

$\mu \quad$ cofficient of viscosity

Pr Prandtl number

Sc Schmidt number

$q_{r} \quad$ radiative heat flux in the y-direction

$R \quad$ radiation parameter

$T \quad$ temperature of the fluid near the plate

$T_{w} \quad$ temperature of the plate

$t^{\prime} \quad$ time

$t \quad$ dimensionless time

$u \quad$ velocity of the fluid in the $\mathrm{x}$-direction

$u_{0} \quad$ velocity of the plate

$U$ dimensionless velocity component in $x$-direction

$x \quad$ spatial coordinate along the plate

$y^{\prime} \quad$ spatial coordinate normal to the plate

$B_{0} \quad$ transverse magnetic field of uniform strength

$\beta \quad$ volumetric coefficient of thermal expansion 
$\beta *$ volumetric coefficient of expansion with concentration

$v \quad$ kinematic viscosity

$\rho \quad$ density of the fluid

$\sigma \quad$ Stefan-Boltzmann constant

$\theta \quad$ dimensionless temperature

erfc complementary error function

$T_{\infty} \quad$ temperature of the fluid far away from the plate

$\eta \quad$ similarity parameter

\section{ACKNOWLEDGMENT}

Our sincere thanks to Principal, Management and Faculty of Mohamed Sathak A J College of Engineering, Chennai for giving their valuable support in making this work successful.

\section{REFERENCES}

[1] W. G. England and A. F. Emery, "Thermal radiation effects on the laminar free convection boundary layer of an absorbing gas," Journal of Heat Transfer, vol. 91, pp. 37-44, 1969.

[2] M. A. Hossain and H. S. Takhar, "Radiation effect on mixed convection along a vertical plate with uniform surface temperature," Heat and Mass Transfer, vol. 31, pp. 243-248, 1996.

[3] A. Raptis and C. Perdikis, "Radiation and free convection flow past a moving plate," International Journal of Applied Mechanics and Enginnering, vol. 4, pp. 817-821, 1999.

[4] U. N. Das, R. K. Deka, and V. M. Soundalgekar, "Radiation effects on flow past an impulsively started vertical infinite plate," Journal of Theoretical Mechanics, vol. 1, pp. 111-115, 1996.

[5] A. S. Gupta, I. PoP, and V. M. Soudalgekar, "Free convection effects on the flow past an accelerated vertical plate in an incompressible dissipative fluid," Rev. Roum. Sci. Techn.-Mec. Apl., vol. 24, pp. 561$568,1979$.

[6] N. G. Kafousias and A. A. Raptis, "Mass transfer and free convection effects on the flow past an accelerated vertical infinite plate with variable suction or injection," Rev. Roum. Sci. Techn.-Mec. Apl., vol. 26, pp. 11-22, 1981.

[7] V. M. Soundalgeka, "Effects of mass transfer on flow past a uniformly accelerated vertical plate," Letters in heat and mass transfer, vol. 9, pp. 65-72, 1982.

[8] A. K. Singh and J. Singh, "Mass transfer effects on the flow past an accelerated vertical plate with constant heat flux," Astrophysics and Space Science, vol. 97, pp. 57-61, 1983.
[9] B. K. Jha and R. Prasad, "Free convection and mass transfer effects on the flow past an accelerated vertical plate with heat sources," Mechanics Research Communications, vol. 17, pp. 143-148, 1990.

[10] R. Muthucumaraswamy, M. Sundar Raj, and V. S. A. Subramanian, "Heat and Mass transfer effects on flow past an accelerated vertical plate with variable mass diffusion," International Journal of Applied Mathematics and Engineering Sciences, vol. 3, no. 1, pp. 55-60, 2009.

[11] M. Muralidharan and R. Muthucumaraswamy, "Thermal radiation on linearly accelerated vertical plate with variable temperature and uniform mass flux," Indian Journal of Science and Technology, vol. 3, pp. 398-401, 2010.

[12] R. Muthucumaraswamy, M. Sundar Raj, V. S. A. Subramanian, "Exact solution of flow past an accelerated infinite vertical plate with uniform heat and mass flux," International Journal of Applied Mechanics and Engineering, vol. 14, no. 2, pp. 585-592, 2009.

[13] R. Muthucumaraswamy, M. Sundar Raj, V. S. A. Subramanian, "Unsteady flow past an accelerated infinite vertical plate with variable temperature and uniform mass diffusion," Int. J. of Appl. Math and Mech., vol. 5, no. 6, pp. 51-56, 2009.

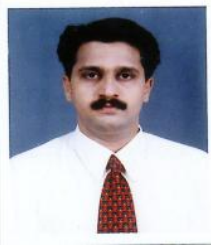

Muralidharan M. was born in Chennai, India on $16^{\text {th }}$ May 1969 and pursuing Ph.D. degree in Sathyabama University,Chennai. He completed M.Sc., and M. Phil., degree from Madras University in April 1991 and August 1997respectively.

He has a total of 22 years of teaching experience. Presently HOD of Maths in Mohamed Sathak A J College of Engineering, Chennai. Five Research papers published in International \& National Journals, Presented three papers in International \& National Conferences. Life member of ISTE and authored One book of Mathematics for undergraduate classes.



R. Muthucumaraswamy was born in Chennai, India on $17^{\text {th }}$ May 1965. He completed M.Sc., degree from Anna University in April 1987, M. Phil., degree from University of Madras in August 1991 and Ph.D. from Anna University, 2001

He has a total of 26 years of teaching experience. Presently HOD of Applied Mathematics in Sri Venkateswara College of Engineering, Chennai. More than 110 Research papers published in International \& National Journals, Published more than 15 papers in International \& National Conferences. He has conducted nearly ten workshops and attended many professional development programmes. Life member of ISTE and he is a board chairman for Mathematics - Central Valuation, Anna University. 